\title{
Parents' Attachment Styles and Adolescents' Regulatory Emotional Self-efficacy: The Mediating Role of Adolescents' Attachment to Parents in China
}

\author{
Yangu Pan ${ }^{1}$. Qiongwen Zhang ${ }^{1}$ - Guangzeng $\mathrm{Liu}^{2} \cdot$ Bingbing $\mathrm{Li}^{3}$. \\ Chuanxing Liu ${ }^{4}$
}

Accepted: 9 September 2021 /Published online: 29 September 2021

(c) The Author(s) 2021, corrected publication 2021

\begin{abstract}
Guided by attachment theory, this longitudinal study examined the mediating role of parent-adolescent attachment on the relation between parents' attachment styles and adolescents' regulatory emotional self-efficacy (RESE, including managing negative affect and expressing positive affect). Five hundred seventy-three Chinese junior high school students (46\% male; aged $11-14$ years, $M=12.76$ years, $S D=0.74$ ) completed measures of RESE at T1, parent-adolescent attachment at T2 (six months later), and RESE at T3 (another six months later), while 573 students' parents (one student only has a parent, 241 fathers and 332 mothers) completed measures of adult attachment styles (anxiety and avoidance) at T1. Results from structural equation modeling indicated that father-adolescent attachment mediated the association between fathers' attachment anxiety and adolescents' self-efficacy beliefs in managing negative affect, while mother-adolescent attachment marginally mediated the relation between mothers' attachment anxiety and adolescents' self-efficacy beliefs in managing negative affect and expressing positive affect. These findings suggest that parents' attachment anxiety could predict their children's attachment to parents, in turn, impacting their children's regulatory emotional self-efficacy.
\end{abstract}

Keywords Adult attachment style $\cdot$ Father-adolescent attachment $\cdot$ Motheradolescent attachment $\cdot$ Regulatory emotional self-efficacy $\cdot$ Early adolescents · China

Qiongwen Zhang

ilxpw@swufe.edu.cn

1 Research Institute of Social Development, Southwestern University of Finance and Economics, No. 555, Liutai Road, Wenjiang District, Chengdu 611130, China

2 Research Center of Mental Health Education \& Faculty of Psychology, Southwest University, Chongqing, China

3 Department of Psychology, Educational College, Shanghai Normal University, Shanghai, China

4 Sichuan Education Evaluation Institute, Chengdu, China 


\section{Introduction}

Regulatory emotional self-efficacy (RESE) is a positive psychological quality referring to self-efficacy beliefs in managing negative affect (NEG) and expressing positive affect (POS). More specifically, NEG refers to beliefs regarding one's ability to alleviate negative emotional states (e.g., anger and despondency) that develop in response to adversity or frustrating events, and to avoid being overcome by these emotions. Conversely, POS refers to beliefs about one's ability to experience or allow oneself to express positive emotions (e.g., joy and pride) in response to success or pleasant events (Caprara et al., 2008). Regulatory emotional self-efficacy plays an important role in adolescent diverse spheres of psychosocial functioning. For instance, POS is positively related with empathy, prosocial behavior, and well-being (Caprara \& Steca, 2005), whereas NEG is negatively associated with anxiety, depressive symptoms, and shyness (Bandura et al., 2003). Additionally, RESE (i.e., emotional competence and self-efficacy) are positive youth development (PYD) attributes which play important role in youth well-being (Zhou, Shek, \& Zhu, 2020; Zhou, Shek, Zhu, \& Dou, 2020).

Family members play importance role in child and adolescent psychosocial development in Chinese societies (Li et al., 2019; Leung \& Fung, 2021). According to attachment theory, children with secure attachment to parents develop a positive internal working model of themselves as loveable and competent (Bowlby, 1969), so that they had higher general self-efficacy (Lu \& Zhang, 2008) and emotional regulation ability (Cassidy, 1994; Mikulincer \& Shaver, 2019), as a result, they could develop higher regulatory emotional self-efficacy (Pan, Zhang, Liu, Ran, \& Wang, 2016a, b). Moreover, according to the intergenerational transmission of attachment, children's attachment to parents could be predicted by their parents' attachment representation, specifically, parents with secure attachment representation are more likely to have children with secure attachment to parents (van Ijzendoorn, 1995; van Ijzendoorn \& Bakermans-Kranenburg, 2018; Verhage et al., 2016). Together, children's attachment to parents might link parents' attachment representation with children's regulatory emotional self-efficacy. Additionally, early adolescence is a time when autonomy from parents is particularly salient for individuals (Steinberg \& Silverberg, 1986). Thus, guided by attachment theory, the present study examined the mediating role of early adolescents' attachment to parents on the association between parents' attachment representation and early adolescents' regulatory emotional self-efficacy.

\section{Attachment and regulatory emotional self-efficacy among adolescents}

Attachment theory assumes that social interactions with primary caregivers form individual internal working models (i.e., mental representations of self and others), which influence individual psychosocial functioning and adaptive outcomes 
across the life span (Bowlby, 1973; Madigan et al., 2016; Zhou, Guo, \& Lu, 2020). During early life stage, children's attachment figures usually are their parents. Ainsworth, Blehar, Waters, and Wall (1978) proposed that there are individual differences in children's patterns of attachment to their parents (caregivers). For children and adolescents, parental attachment (attachment to parents) is used to represent the individual differences in children's/adolescent's attachment relationship quality with parents (Armsden \& Greenberg, 1987).

According to attachment theory, children and adolescents with secure attachment to caregivers develop positive internal working models so that they perceive themselves as loveable and competent (Bowlby, 1969), in turn, they have more positive self-evaluation (Song et al., 2009; Wilkinson, 2004). Previous study found early adolescents with secure attachment to parents had higher general self-efficacy (Lu \& Zhang, 2008). Moreover, attachment theory assumes that children's emotion regulation ability stems from their caregiver's sensitivity to the children's suffering (Bowlby, 1969; Calkins \& Leerkes, 2011; Mikulincer et al., 2003). Previous studies also indicate that children with secure attachment are better able to regulate their emotions (Cassidy, 1994; Kerns et al., 2007; Mikulincer \& Shaver, 2019; Sroufe, 2005). Together, children and adolescents with secure attachment to parents may develop higher regulatory emotional self-efficacy. In fact, one study directly demonstrated that secure attachment to parents was positively associated with regulatory emotional self-efficacy among early adolescents (Pan, 2016a, b).

\section{Parents' attachment styles and adolescents' attachment to parents}

According to the intergenerational transmission of attachment, parents' attachment representation could predict the security or insecurity of their children's attachment to parents (van Ijzendoorn, 1995; Verhage et al., 2016). Attachment relationships with parents in childhood and thereafter serve as mental models that shape parents' interactions and attachment relationships with their offspring (Main et al., 1985). The current mental representation of childhood attachment experiences, that is, adult attachment, impacts their children's attachment relationship with them (van Ijzendoorn \& Bakermans-Kranenburg, 2018). During the 1980s, two independent lines of research were initiated to explore the individual differences of attachment in adulthood. First, Main et al. (1985) developed the Adult Attachment Interview (AAI) to measure the current representation of attachment in adults. Meta-analytical and empirical studies have demonstrated that an adult's attachment representations assessed by AAI is related to his or her child's attachment classification in the Strange Situation (Behrens et al., 2016; van Ijzendoorn, 1995). Specifically, adults classified as secure in the AAI are more likely to have a child who is categorized as secure in the Strange Situation relative to adults classified as insecure.

Second, Hazan and Shaver (1987) developed a simple three-category (secure, avoidant, anxious/ambivalent) self-report measure to assess representation of attachment in adults - referred to as adult attachment styles. Adult attachment styles are conceptualized as "systematic patterns of expectations, needs, emotions, emotionregulation strategies, and social behavior" in close relationships (e.g., with family 
members, romantic partners, and close friends; Mikulincer \& Shaver, 2007). Subsequent psychometric research suggested that variation in adult attachment styles is better assessed by dimensional, rather than categorical, self-report measures (attachment-related anxiety and avoidance in close relationships; Brennan et al., 1998). High attachment anxiety reflects an intense fear of rejection and abandonment, a strong desire for relationship closeness, and high preoccupation with relationship needs (Shaver \& Mikulincer, 2002). Conversely, high attachment avoidance reflects discomfort with intimacy, dependency, and emotional disclosure in close relationships. A high score on one or both of these dimensions is considered to reflect greater attachment insecurity, while lower scores on both dimensions reflect greater attachment security.

Although the AAI and attachment style measures come from the same theoretical tradition and are regarded as measures of "adult attachment", they are different in some respects and are not strongly related to each other (Roisman et al., 2007). For the intergenerational transmission of attachment, it is necessary to examine the association between parents' attachment styles and their children's attachment security. A review has suggested that parents' attachment styles were related to parenting behaviors, emotions, and cognitions (Jones et al., 2015a, b). Specifically, studies have shown that avoidant adults have less sensitive, responsive, and supportive parental behavior (Rholes et al., 1995; Selcuk et al., 2010), and hold more negative views of parenthood and of their children (Rholes et al., 1997). Studies also found that anxious mothers have less responsive maternal behavior (Goodman et al., 1997), and frequently miss their children's signals and interfering with their children's exploration (Selcuk et al., 2010). Moreover, parental sensitivity and responsiveness are among the most important predictors of child attachment security (Ainsworth et al., 1978; De Wolff \& van IJzendoorn, 1997). Therefore, parents' attachment styles could be associated with their children's attachment security.

\section{Different effects of father-adolescent and mother-adolescent attachment on adolescent psychosocial functioning}

Although children's primary attachment figure usually are mothers, recently an increasing body of studies suggest that the involvement of fathers plays an important role in children's development (Paquette et al., 2013), including in Chinese culture (Pan et al., 2020). Fathers seem to play a major role in the process of opening children up to the outside world, which is particularly linked to the development of autonomy and the management of risk-taking during the exploration of physical and social environments, fostering the development of physical, and social skills and self-assertiveness (Grossmann et al., 2002; Paquette et al., 2013). Indeed, empirical studies have demonstrated that father-adolescent attachment had a different impact from that of mother-adolescent attachment on social functioning in adolescents. For example, one study found that, relative to mother-adolescent attachment, fatheradolescent attachment had stronger effect on social self-efficacy in early adolescents (Coleman, 2003). Another study found that father-adolescent attachment was a more 
important predictor of social competence than was mother-adolescent attachment among late adolescents (Rice et al., 1997).

\section{Present Study}

Our study attempted to address the following issues: (1) whether parents' attachment style could predict adolescents' attachment to parents, in turn, predicting adolescents' RESE? (2) whether the relations of these variables were different between fathers and mothers? We used a longitudinal study to answer these questions because longitudinal design allows for an accurate analysis of mediating effects by controlling for the baseline values of outcome variable (Maxwell \& Cole, 2007). Specifically, a true mediation test would require at least three time points of data (i.e., measuring the predictor at the initial time point, the mediating variable at a point subsequent to the predictor, and the outcome at a point subsequent to the mediator; Maxwell \& Cole, 2007).

Given that parents' attachment style consists of two dimensions (anxiety and avoidance), and that adolescents' attachment to father and mother have different effects on adolescents' psychosocial functioning, we created four separate models (see Fig. 1-2) to examine interrelations between the variables. Based on the above literature review, we proposed four hypotheses. First, we hypothesized that adolescents' attachment to father mediates the association between fathers' attachment anxiety and adolescents' RESE (including POS and NEG) (Hypothesis 1). Second, we hypothesized that adolescents' attachment to father mediates the association between fathers' attachment avoidance and adolescents' RESE (Hypothesis 2). Third, we hypothesized that adolescents' attachment to mother mediates the association between mothers' attachment anxiety and adolescents' RESE (Hypothesis 3). Fourth, we predicted that adolescents' attachment to mother mediates the association between mothers' attachment avoidance and adolescents' RESE (Hypothesis 4).

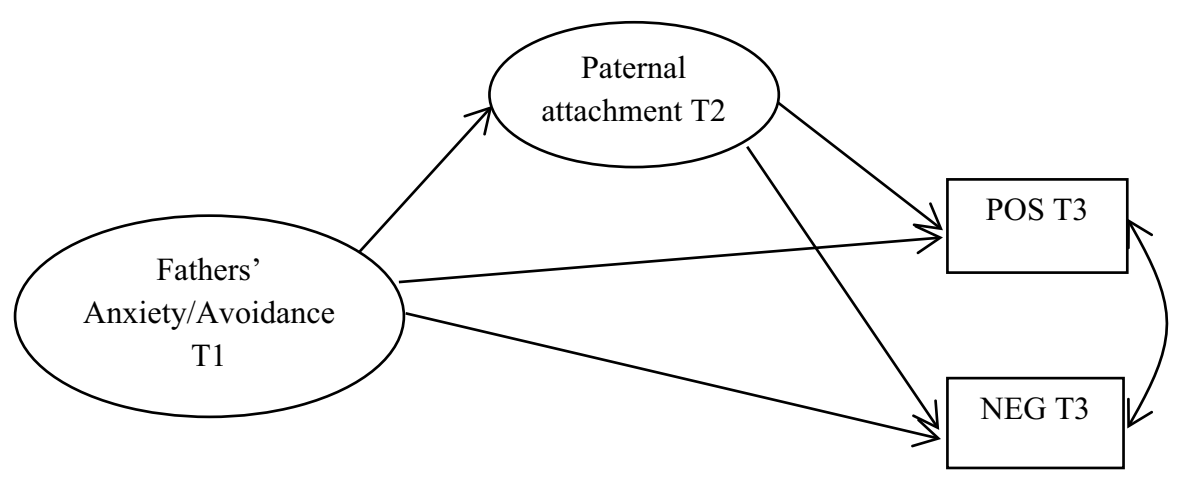

Fig. 1 Longitudinal relations of fathers' attachment anxiety or avoidance (T1) to adolescents' POS and NEG (T3) through adolescent paternal attachment (T2). Note. Fathers' Anxiety/Avoidance T1: fathers' attachment anxiety or avoidance at Time 1; Paternal attachment T2: adolescent paternal attachment at Time 2; POS T3: adolescents' POS at Time 3; NEG T3: adolescents' NEG at Time 3. 


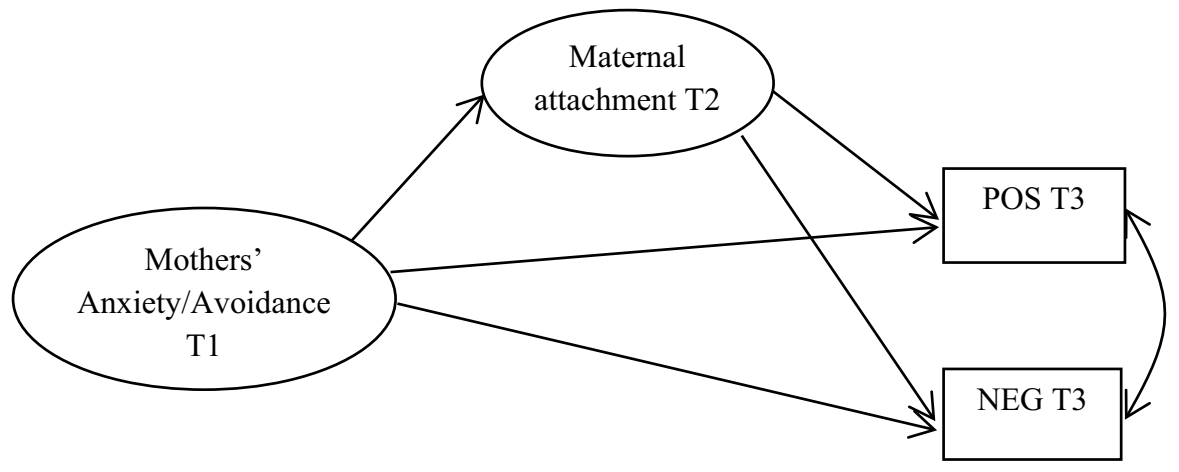

Fig. 2 Longitudinal relations of mothers' attachment anxiety or avoidance (T1) to adolescents' POS and NEG (T3) through adolescent maternal attachment (T2). Note. Mothers' Anxiety/Avoidance T1: mothers' attachment anxiety or avoidance at Time 1; Maternal attachment T2: adolescent maternal attachment at Time 2; POS T3: adolescents' POS at Time 3; NEG T3: adolescents' NEG at Time 3.

\section{Method}

\section{Participants and Procedure}

We selected early adolescents and their parents as participants. The early adolescents were recruited from three junior high schools in southwest China: one in Chengdu City, Sichuan province (Chengdu is a national center city); one in the Beibei District of Chongqing municipality (Beibei is a medium-sized city); and one in Dazhu County, Sichuan province (Dazhu is a remote and backward county town). We recruited only one parent (one main caregiver, such as father or mother) for each adolescent, and they participated only at the initial data collection point (i.e., T1). At T1, 710 students and 650 of their parents were present, but only 630 students were present at the second data collection point, six months later (T2). In total, 600 students provided complete data at the third collection point, which took place after another six months (T3). The final sample comprised 573 students and their parents (241 fathers and 332 mothers); 137 students were lost because they were absent on the assessment days or their parents declined to participate at T1. The two groups (573 and 137 students) did not differ significantly in any of the study variables (i.e. parents' attachment styles, adolescent parental attachment, RESE). Students in the final sample were 11-14 years old $(M=12.76$ years, $S D=0.74)$. Two hundred ninety-six students were in 7 th grade, while the remaining 277 were in 8 th grade. Two hundred sixty-five students were boys, and 308 were girls. In addition, two hundred and forty-one fathers in the final sample were 32-73 years old $(M=40.97$ years, $S D=4.58)$; for the highest education level, $55.7 \%$ of fathers were junior high school or below, $25 \%$ were senior high school, $19.3 \%$ were college degree or above. Three hundred and thirty-two mothers in the final sample were $31-52$ years old $(M=39.87$ years, $S D=4.27$ ); for the highest education level, $50.9 \%$ of mothers were junior high school or below, $29.7 \%$ were senior high school, $19.4 \%$ were college degree 
or above. All fathers and mothers are middle-class and working class. Both students and parents were predominantly of Han ethnicity.

This study was approved by the Research Ethics Committee at the lead researcher's university. Following the guideline of the Research Ethics Committee, written consent was first obtained from the heads of school and parents, after which all willing students provided their oral consent. At T1, T2, and T3, students completed a self-reported questionnaire in a 40-minute class at school with the guidance provided by trained graduate researchers. At T1, students took home the adult attachment style questionnaire (used to measure parents' attachment style) for a parent (either the father or mother) to complete. The parent survey sealed in an envelope was returned to the researchers on the following day.

\section{Measures}

Adult attachment styles Parents' attachment styles were measured using the short version of the Experiences in Close Relationships Scale (ECR; Wei et al., 2007), a 12-item scale assessing individuals' typical degree of attachment-related anxiety and avoidance in close relationships (e.g., with family members, romantic partners, or close friends). The subscale of anxiety (6 items) measures the extent to which a person strongly desires closeness in their relationships and worries about being rejected, abandoned, or unloved (e.g., "I worry that romantic partners won't care about me as much as I care about them"). The subscale of avoidance (6 items) assesses the extent to which a person is uncomfortable with closeness, intimacy, and emotional disclosure in close relationships (e.g., "I try to avoid getting too close to my partner"). Each item was rated by parents on a 7-point frequency response scale ranging from 1 (disagree strongly) to 7 (agree strongly). Higher scores indicate greater attachment anxiety or avoidance. The reliability and validity of this questionnaire were demonstrated in a previous study (Wei et al., 2007). In the current study, we ended up deleting five items (two items on anxiety and three items on avoidance) because of their low item-total correlations. As a result, the Cronbach's alphas at $\mathrm{T} 1$ for the subscale of anxiety were .69 (fathers) and .75 (mothers), while those for the subscale of avoidance were .87 (fathers) and .80 (mothers). In the analysis, we conducted the structural equation modeling (SEM) using latent variables to rule out the possibility of measurement errors. The seven items left in this scale were used as indicators of the latent variables of attachment anxiety (four items) and attachment avoidance (three items).

Adolescent parental attachment The attachment relationship between adolescents and their parent was assessed using the parent subscales of the short version of the Inventory of Parent and Peer Attachments (IPPA; Armsden \& Greenberg, 1987). This adolescent self-report questionnaire assesses the extent to which adolescents feel securely attached with their fathers and mothers. It has two sections - attachment with mothers and fathers - with 12 items each. This instrument specifically measures adolescents' trust in the availability and sensitivity of the attachment figure (trust, four items), the quality of communication (communication, four items), 
and the degree of anger and alienation (alienation, four items) in the relationship with attachment figure. Examples of items for each subscale are as follows: for trust, "My father/mother respects my feelings"; for communication, "If my father/ mother knows something is bothering me, he/she asks me"; and for alienation, "I don't get much attention from my father/mother." All of the items are rated using a five-point frequency response scale $(1=$ almost never $\ldots 5=$ almost always $)$. The short version of the IPPA has proven to be reliable and valid in previous studies, including several with Chinese samples (Pan et al., 2017; Pan et al., 2016a, b; Raja et al., 1992). The Cronbach's alphas at T2 in the present study for the paternal and maternal attachment scales were as follows, respectively: trust $(0.70,0.73)$, communication $(0.65,0.63)$, and alienation $(0.66,0.60)$. In the SEM, we used the three subscales (trust, communication, alienation) as indicators of the latent variables of paternal or maternal attachment.

Regulatory emotional self-efficacy We used the RESE scale, which was devised by Caprara et al. (2008), to measure adolescents' RESE. This self-report scale comprises 12 items in two subscales: POS (4 items) and NEG (8 items). The NEG subscale is further made up of the lower-order subscales of anger-irritation (ANG, 4 items) and despondency-distress (DES, 4 items). Examples of items include "How well can you express joy when good things happen to you?" (POS) and "How well can you keep from getting discouraged in the face of difficulties?" (DES). All items are rated using a five-point frequency response scale $(1=$ not well at all $\ldots 5=$ very well). The RESE has proven to be reliable and valid in previous studies, including several with Chinese samples (Caprara et al., 2008; Pan et al., 2016a, b). The Cronbach's alphas at T3 in the present study for the RESE were 0.81 (POS) and 0.85 (NEG). We used the POS and NEG subscales as the two observed variables in the SEM.

Demographic Measures We collected demographic variables of students' gender, grade, age, and their parents' gender at T1.

\section{Data Analytic Strategy}

First, descriptive and correlation analyses were conducted for the variables of interest for the total sample. Second, we examined the mediating role of adolescent paternal/maternal attachment in the association between fathers'/mothers' attachment styles and adolescent RESE by using SEM. We tested four separate models for fathers' attachment anxiety (see Fig. 3), fathers' attachment avoidance (see Fig. 4), mothers' attachment anxiety (see Fig. 5), and mothers' attachment avoidance (see Fig. 6). Additionally, we controlled for adolescents' RESE at T1 and gender (Lu et al., 2021), while we did not controlled for adolescents' age because it was not related with outcome variables.

We used Mplus 7 (Muthén \& Muthén, 2012) to fit the proposed models to the data. The SEM was performed using the robust maximum likelihood (MLR) estimator to account for the non-normality of the data. Indirect effects were examined 


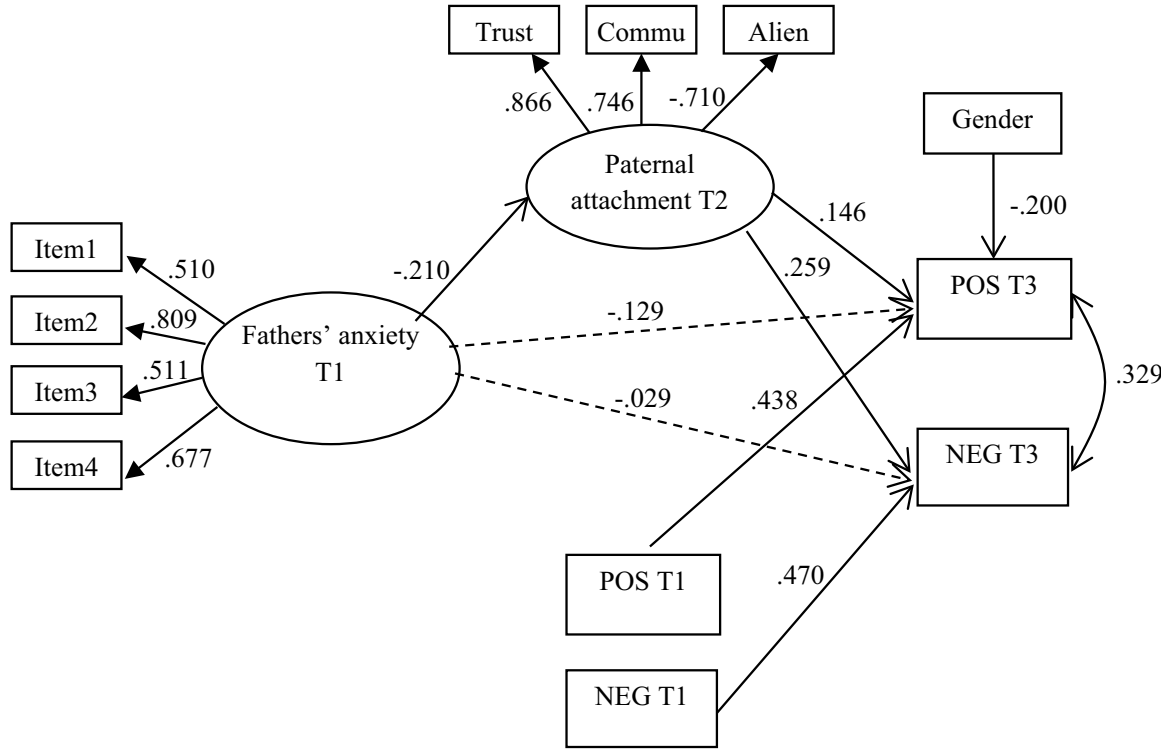

Fig. 3 Longitudinal relationships of fathers' attachment anxiety (T1) to adolescents' POS and NEG (T3) through adolescent paternal attachment (T2). Note. Paternal attachment T2: adolescent paternal attachment at Time 2; POS T3: adolescents' POS at Time 3; NEG T3: adolescents' NEG at Time 3; POS T1: adolescents' POS at Time 1; NEG T1: adolescents' NEG at Time 1; Gender: adolescents' gender with 0 = girl, 1 = boy. Solid line: significant path; Dotted line: not significant path.

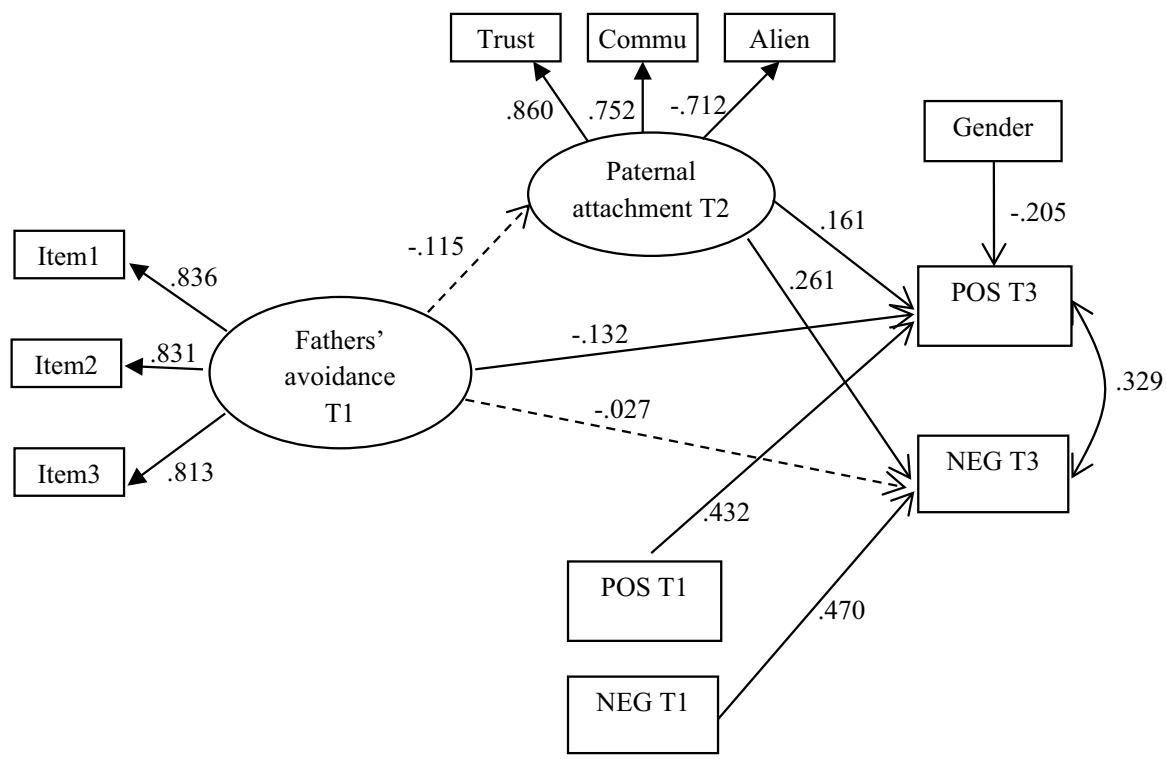

Fig. 4 Longitudinal relationships of fathers' attachment avoidance (T1) to adolescents' POS and NEG (T3) through adolescent paternal attachment (T2). Note. Paternal attachment T2: adolescent paternal attachment at Time 2; POS T3: adolescents' POS at Time 3; NEG T3: adolescents' NEG at Time 3; POS T1: adolescents' POS at Time 1; NEG T1: adolescents' NEG at Time 1; Gender: adolescents' gender with $0=$ girl, $1=$ boy. Solid line: significant path; Dotted line: not significant path. 


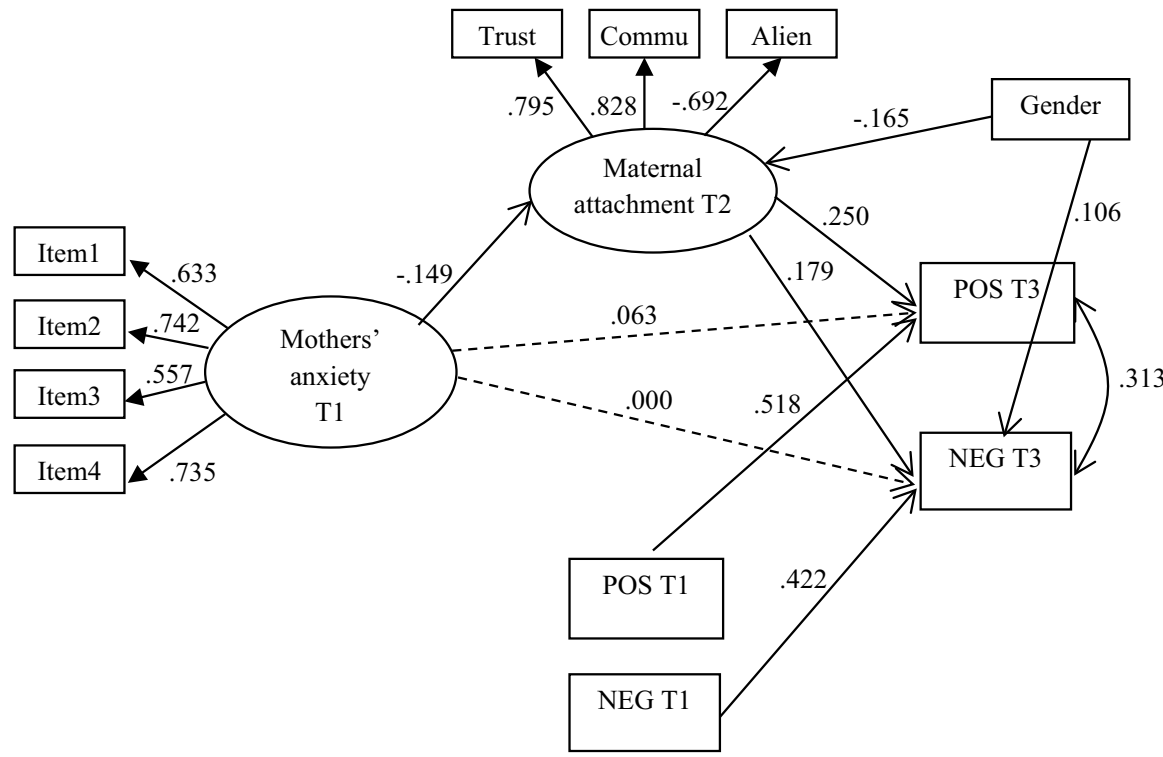

Fig. 5 Longitudinal relationships of mothers' attachment anxiety (T1) to adolescents' POS and NEG (T3) through adolescent maternal attachment (T2). Note. Maternal attachment T2: adolescent maternal attachment at Time 2; POS T3: adolescents' POS at Time 3; NEG T3: adolescents' NEG at Time 3; POS T1: adolescents' POS at Time 1; NEG T1: adolescents' NEG at Time 1; Gender: adolescents' gender with $0=$ girl, $1=$ boy. Solid line: significant path; Dotted line: not significant path.

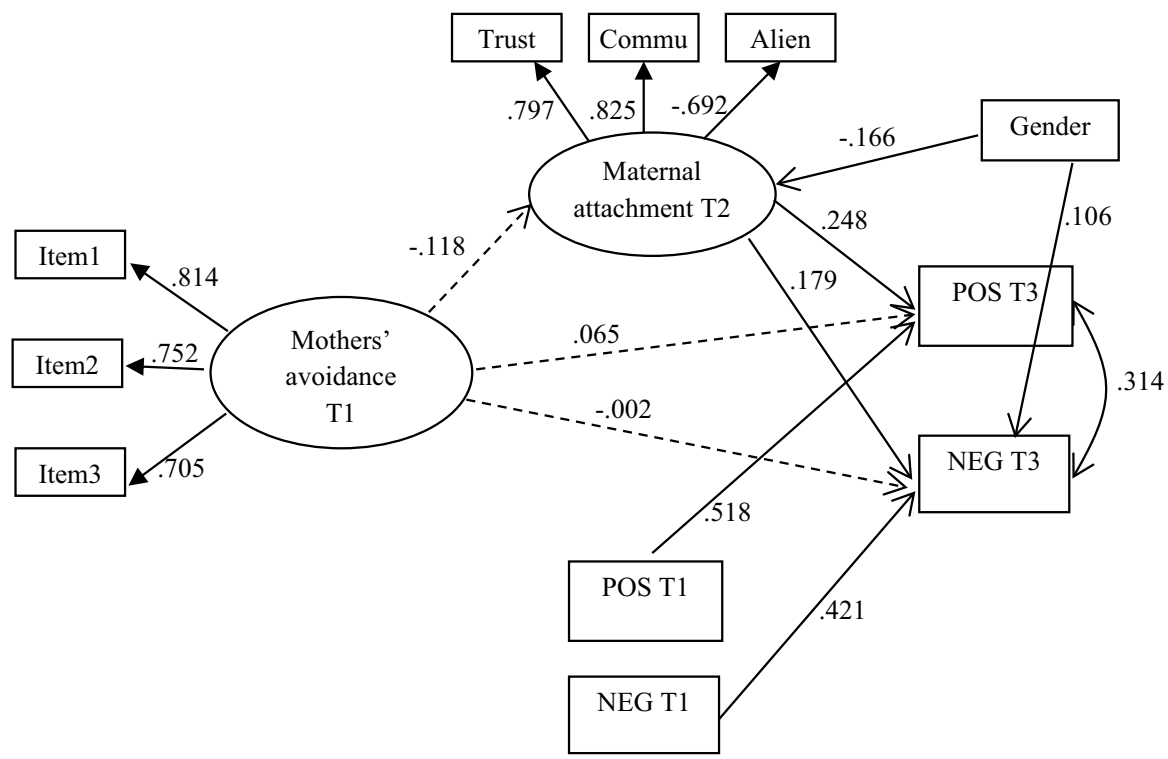

Fig. 6 Longitudinal relationships of mothers' attachment avoidance (T1) to adolescents' POS and NEG (T3) through adolescent maternal attachment (T2). Note. Maternal attachment T2: adolescent maternal attachment at Time 2; POS T3: adolescents' POS at Time 3; NEG T3: adolescents' NEG at Time 3; POS T1: adolescents' POS at Time 1; NEG T1: adolescents' NEG at Time 1; Gender: adolescents' gender with $0=$ girl, $1=$ boy. Solid line: significant path; Dotted line: not significant path. 
using the bootstrapping method, which is a nonparametric approach that allows for hypothesis testing as well as the calculation of effect sizes (Preacher \& Hayes, 2008). To evaluate the fit of the models to the data, we examined several standard fit indices, including the comparative fit index (CFI), Tucker-Lewis index (TLI), root mean square error of approximation (RMSEA), and standardized root mean square residual (SRMR). Good model fit was indicated by values of greater than .90 for the CFI and TLI and smaller than .06 and .08 for the RMSEA and SRMR, respectively (Hu \& Bentler, 1999). Additionally, the $\chi^{2}$ value was not regarded as fit indices, because it was influenced easily by sample size.

\section{Results}

\section{Descriptive and Correlation Analyses}

Tables 1 and 2 shows the means, standard deviations, and bivariate correlations for all variables for fathers and mothers, respectively. We found that fathers' attachment anxiety at T1 was negatively related with adolescents' paternal attachment at T2, and that both fathers' attachment anxiety and avoidance at T1 were negatively associated with adolescents' POS at T3. Moreover, adolescents' paternal attachment at T2 was positively related with adolescents' POS and NEG at T3. Notably, adolescent gender ( $0=$ girl, $1=$ boy) was negatively related with adolescents' POS at T3.

As for mothers' attachment style, high mothers' attachment anxiety and avoidance at T1 were associated with low adolescents' maternal attachment at T2. Moreover, low adolescents' maternal attachment at T2 was related with low adolescents' POS and NEG at T3. Additionally, we found that adolescent gender $(0=$ girl, $1=$ boy) was negatively related with adolescents' maternal attachment at T2, and marginally positively associated with adolescents' NEG at T3.

Table 1 Means, standard deviations, and bivariate correlations of fathers' attachment anxiety and avoidance at T1, adolescent paternal attachment at T2, and adolescents' POS and NEG at T1 and T3

\begin{tabular}{llllllllll}
\hline Variables & $M$ & $S D$ & 1 & 2 & 3 & 4 & 5 & 6 & 7 \\
\hline 1 Fathers' anxiety T1 & 9.36 & 5.09 & - & & & & & \\
2 Fathers' avoidance T1 & 6.21 & 4.17 & $.77^{* * *}$ & - & & & & \\
3 Adolescents' POS T1 & 16.03 & 3.14 & -.08 & $-.12^{\dagger}$ & - & & & \\
4 Adolescents' NEG T1 & 26.67 & 6.46 & -.02 & -.04 & $.34^{* * *}$ & - & & & \\
5 Paternal attachment T2 & 45.49 & 8.22 & $-.15^{*}$ & -.09 & $.20^{* *}$ & $.29^{* * *}$ & - & & \\
6 Adolescents' POS T3 & 15.78 & 3.23 & $-.17^{* *}$ & $-.19^{* *}$ & $.50^{* * *}$ & $.18^{* *}$ & $.25^{* * *}$ & - & \\
7 Adolescents' NEG T3 & 27.40 & 6.07 & -.07 & -.07 & $.26^{* * *}$ & $.53^{* * *}$ & $.35^{* * *}$ & $.38^{* * *}$ & - \\
8 Adolescents' Gender & .50 & .50 & .07 & .01 & -.06 & .08 & -.03 & $-.23^{* * *}$ & .09 \\
\hline
\end{tabular}

Note. Paternal attachment T2: adolescent paternal attachment at Time 2; POS: perceived capability of expressing positive affect; NEG: perceived capability of regulating negative affect. Gender was coded with $0=$ girl; $1=$ boy. ${ }^{\dagger} p<.08,{ }^{*} p<0.05$, $* * p<0.01,{ }^{*} * * p<0.001 . N=241$. 
Table 2 Means, standard deviations, and bivariate correlations of mothers' attachment anxiety and avoidance at T1, adolescent maternal attachment at T2, and adolescents' POS and NEG at T1 and T3

\begin{tabular}{llllllllll}
\hline Variables & $M$ & $S D$ & 1 & 2 & 3 & 4 & 5 & 6 & 7 \\
\hline 1 Mothers' anxiety T1 & 9.71 & 5.39 & - & & & & & & \\
2 Mothers' avoidance T1 & 6.51 & 4.15 & $.76^{* * *}$ & - & & & & & \\
3 Adolescents' POS T1 & 16.25 & 3.22 & .09 & .07 & - & & & & \\
4 Adolescents' NEG T1 & 26.34 & 6.68 & .02 & -.02 & $.31^{* * *}$ & - & & & \\
5 Maternal attachment T2 & 47.33 & 7.98 & $-.14^{*}$ & $-.11^{*}$ & $.11^{*}$ & $.26^{* * *}$ & - & & \\
6 Adolescents' POS T3 & 16.11 & 3.38 & .06 & .06 & $.57^{* * *}$ & $.29 * *$ & $.27^{* * *}$ & - & \\
7 Adolescents' NEG T3 & 26.99 & 6.32 & -.01 & -.02 & $.27^{* * *}$ & $.49 * * *$ & $.25^{* * *}$ & $.44^{* * *}$ & - \\
8 Adolescents' Gender & .44 & .50 & $.10^{\dagger}$ & .08 & -.08 & .08 & $-.15^{* *}$ & -.10 & $.10^{\dagger}$ \\
\hline
\end{tabular}

Note. Maternal attachment T2: adolescent maternal attachment at Time 2; POS: perceived capability of expressing positive affect; NEG: perceived capability of regulating negative affect. Gender was coded with $0=$ girl; $1=$ boy. ${ }^{\dagger} p<.08,{ }^{*} p<0.05, * * p<0.01, * * * p<0.001 . N=332$.

\section{Parents' Attachment Styles and Adolescent RESE: The Mediating Role of Adolescent Parental Attachment}

Fathers' anxiety or avoidance and adolescents' RESE: The mediating role of adolescent paternal attachment The model describing the longitudinal effect of fathers' attachment anxiety at T1 on adolescents' RESE at T3 via adolescent paternal attachment at T2 (see Fig. 3) showed a good fit to the data, $\chi^{2}(45)=76.73, p=0.002$, $\mathrm{CFI}=0.947$, TLI $=0.926$, RMSEA $=0.054(90 \% C I=0.032,0.074), \mathrm{SRMR}=$ 0.076. The test of the indirect effects indicated that adolescent paternal attachment significantly mediated the relation between fathers' anxiety and adolescents' NEG, $\beta$ $=-.054,95 \% C I=[-.102,-.006], p=.025$, but did not mediate the relation between fathers' anxiety and adolescents' POS, $\beta=-.031,95 \% C I=[-.069, .007], p=.112$. In addition, the direct effects of fathers' anxiety on adolescents' POS and NEG were not significant.

Similarly, the model of the longitudinal effect of fathers' attachment avoidance at T1 on adolescents' RESE at T3 via adolescent paternal attachment at T2 (see Fig. 4) also showed a good fit to the data, $\chi^{2}(35)=63.20, p=0.002$, CFI $=0.960$, $\mathrm{TLI}=0.940, \mathrm{RMSEA}=0.058(90 \% C I=0.034,0.080), \mathrm{SRMR}=0.078$. The test of the indirect effects revealed that adolescent paternal attachment did not mediate the effects of fathers' avoidance on adolescents' NEG, $\beta=-.030,95 \% C I=[-.069$, $.009], p=.132$, and POS, $\beta=-.019,95 \% C I=[-.048, .011], p=.218$. Additionally, the direct effect of fathers' avoidance on adolescents' POS was significant, $\beta=$ $-.132, \mathrm{SE}=.065, p=.044$, however, that was non-significant for NEG.

Mothers' anxiety or avoidance and adolescents' RESE: The mediating role of adolescent maternal attachment The model of the longitudinal effect of mothers' anxiety at T1 on adolescents' RESE at T3 via adolescent maternal attachment at T2 (see Fig. 5) showed a good fit to the data, $\chi^{2}(45)=83.58, \mathrm{p}<0.001, \mathrm{CFI}=0.956$, TLI $=0.939, \mathrm{RMSEA}=0.051(90 \% C I=0.033,0.068), \mathrm{SRMR}=0.068$. The tests of 
the indirect effects indicated that adolescent maternal attachment marginally mediated the relations between mothers' anxiety and adolescents' POS, $\beta=-.037,95 \%$ $C I=[-.077, .002], p=.053$, and NEG, $\beta=-.027,95 \% C I=[-.059, .005], p=.084$. In addition, the direct effects of mothers' anxiety on adolescents' POS and NEG were not significant.

Similarly, the model of the longitudinal effect of mothers' avoidance at T1 on adolescents' RESE at T3 via adolescent maternal attachment at T2 (see Fig. 6) also showed a good fit to the data, $\chi^{2}(35)=81.50, p<0.001$, CFI $=0.946$, TLI $=$ $0.919, \mathrm{RMSEA}=0.063(90 \% C I=0.045,0.081), \mathrm{SRMR}=0.071$. The tests of the indirect effects revealed that adolescent maternal attachment did not mediate the relations between mothers' avoidance and adolescents' NEG, $\beta=-.021,95 \% C I=$ $[-.051, .009], p=.129$, and POS, $\beta=-.029,95 \% C I=[-.067, .008], p=.102$. Also, the direct effects of mothers' avoidance on adolescents' POS and NEG were not significant. Additionally, Table 3 shows the results of indirect effects in all analyses.

\section{Discussion}

We examined whether adolescent parental attachment mediate the association between parents' attachment styles and adolescents' RESE in a longitudinal study. The results showed that adolescent paternal attachment mediated the longitudinal association between fathers' attachment anxiety and adolescents'

Table 3 Standardized indirect effects of fathers' (mothers') attachment style at T1 on adolescents' POS and NEG at T3 via adolescent paternal (maternal) attachment at T2

\begin{tabular}{|c|c|c|c|c|}
\hline Indirect effect & $\begin{array}{l}\beta \text { (Standardized } \\
\text { indirect effect) }\end{array}$ & $S E$ & $p$ & $\begin{array}{l}95 \% \text { CI Stand- } \\
\text { ardized indirect } \\
\text { effect }\end{array}$ \\
\hline $\begin{array}{l}\text { From Fathers' anxiety T1 to POS T3 } \\
\text { via Paternal attachment T2 }\end{array}$ & -.031 & .019 & .112 & $-.069, .007$ \\
\hline $\begin{array}{l}\text { From Fathers' anxiety T1 to NEG T3 } \\
\text { via Paternal attachment T2 }\end{array}$ & -.054 & .024 & .025 & $-.102,-.006$ \\
\hline $\begin{array}{l}\text { From Fathers' avoidance } \mathrm{T} 1 \text { to POS T3 via Paternal } \\
\text { attachment T2 }\end{array}$ & -.019 & .015 & .218 & $-.048, .011$ \\
\hline $\begin{array}{l}\text { From Fathers' avoidance T1 to NEG T3 via Paternal } \\
\text { attachment T2 }\end{array}$ & -.030 & .020 & .132 & $-.069, .009$ \\
\hline $\begin{array}{l}\text { From Mothers' anxiety T1 to POS T3 } \\
\text { via Maternal attachment T2 }\end{array}$ & -.037 & .019 & .053 & $-.077, .002$ \\
\hline $\begin{array}{l}\text { From Mothers' anxiety T1 to NEG T3 } \\
\text { via Maternal attachment T2 }\end{array}$ & -.027 & .015 & .084 & $-.059, .005$ \\
\hline $\begin{array}{l}\text { From Mothers' avoidance T1 to POS T3 via Maternal } \\
\text { attachment T2 }\end{array}$ & -.029 & .018 & .102 & $-.067, .008$ \\
\hline $\begin{array}{l}\text { From Mothers' avoidance T1 to NEG T3 via Maternal } \\
\text { attachment T2 }\end{array}$ & -.021 & .014 & .129 & $-.051, .009$ \\
\hline
\end{tabular}

Note. POS T3: adolescents' POS at Time 3; NEG T3: adolescents' NEG at Time 3. 
self-efficacy beliefs in managing negative affect. Moreover, adolescent maternal attachment marginally mediated the longitudinal associations between mothers' attachment anxiety and adolescents' self-efficacy beliefs in managing negative affect and expressing positive affect. These findings together suggest that both fathers' and mothers' attachment anxiety could influence early adolescents' RESE via adolescent parental attachment.

\section{Fathers' Attachment Styles and Adolescents' RESE: The Mediating Role of Adolescents' Paternal Attachment}

Results indicated that adolescents' paternal attachment mediated the longitudinal effect of fathers' attachment anxiety on adolescents' NEG. This partially supports Hypothesis 1 . Anxiously attached parents typically miss their children's signals (Selcuk et al., 2010), which may cause children to develop insecure attachment to father, in turn, leading to lower NEG (Pan et al., 2016a, b). This result also supports attachment theory which argues that parents' attachment representation could be transmitted to their children (Verhage et al., 2016). Previous studies obtained somewhat similar results. For instance, one study found that fathers' romantic attachment status influenced children's attachment to fathers (Roelofs et al., 2008), another study found that fathers' attachment anxiety influenced adolescents' substance use via parental knowledge of adolescent activities (Jones et al., 2015a, b). However, we found no significant mediating effect of adolescent paternal attachment on the longitudinal association between fathers' attachment anxiety and adolescents' POS. We suspect that this because the effect of adolescent paternal attachment on POS is weak. This result is consistent with a previous study (Pan et al., 2016a, b).

Moreover, results indicated that adolescent paternal attachment did not mediate the longitudinal association between fathers' attachment avoidance and adolescents' POS/NEG. Further, fathers' attachment avoidance did not predict adolescent paternal attachment. This result was inconsistent with our prediction (Hypothesis 2). In Chinese culture, most fathers have few caring responsibilities and maintain an emotional distance from their children, thus causing many children to develop low levels of attachment to their fathers (Pan et al., 2016a, b). As a result, fathers' attachment avoidance may have less influence on adolescents' attachment to their fathers. One study has also shown that only fathers' attachment anxiety, not attachment avoidance, negatively predicted children's secure attachment to fathers (Bi et al., 2018).

Although fathers' attachment avoidance did not impact adolescent POS/NEG through adolescent attachment to father, results indicated that fathers' attachment avoidance had a direct negative effect on adolescents' POS. This result suggested that fathers' attachment avoidance might influence adolescents' POS through other variables, rather than father-adolescent attachment. Avoidant fathers rarely display positive affect in response to successes or pleasant events (Rholes et al., 1997), which may cause adolescents to learn to do the same. As a result, adolescents with avoidant fathers may develop weak self-efficacy beliefs in expressing positive affect. 


\section{Mothers' Attachment Styles and Adolescents' RESE: The Mediating Role of Adolescents' Maternal Attachment}

Results indicated that adolescent maternal attachment marginally mediated the longitudinal association between mothers' attachment anxiety and adolescents' POS/NEG. This result basically supports Hypothesis 3 . The finding indicates that mothers' attachment anxiety negatively predicted adolescents' maternal attachment, which in turn influenced adolescents' POS or NEG. This result also supports attachment theory which argues that parents' attachment representation can be transmitted to their children (Verhage et al., 2016). Mothers with attachmentrelated anxiety had less responsive maternal behavior (Goodman et al., 1997), and frequently miss their children's signals (Selcuk et al., 2010), as a result, their children would develop insecure attachment to mothers.

Consistent with the results for fathers' avoidance, adolescent maternal attachment did not mediate the longitudinal association between mothers' attachment avoidance and adolescents' POS/NEG. This result leads us to reject Hypothesis 4. Like with the association for fathers, we attribute this result to the lack of a significant effect of mothers' attachment avoidance on adolescent maternal attachment. Avoidant adults prefer to maintain physical and psychological distance from close relationship partners, and are often uncomfortable with others depending on them (Mikulincer \& Shaver, 2007). Given that early adolescence is a time when autonomy from parents is particularly salient for individuals (Steinberg \& Silverberg, 1986), early adolescents may be reluctant to keep as close a relationship with their mothers as in childhood. Thus, mothers' avoidance might have less of an adverse influence on early adolescents' attachment to mothers.

\section{Strengths and Limitations}

This study may have several noteworthy strengths. First, this may be one of the first studies to explicitly test the mediating role of adolescents' parental attachment on the relation between parents' attachment style and adolescents' RESE. And, we investigated the effects of both fathers' and mothers' attachment styles on adolescents' paternal and maternal attachment. Second, as attachment to parents (i.e., bonding) and regulatory emotional self-efficacy (i.e., emotional competence and self-efficacy) are positive youth development (PYD) attributes (Qi et al., 2020; Shek et al., 2019a, b), the present findings reinforce the importance of strengthening PYD attributes in adolescent development. Theoretically, the findings help social scientists to formulate new models on the topic. Third, we used both adolescent-report (adolescents' attachment to parents and RESE) and parent-report (parents' attachment styles) measures, thus reducing the problems of common-method variance and increasing the internal validity of the findings. Finally, the longitudinal design enabled a more accurate analyses of the mediating effects by controlling for the baseline values of adolescents' RESE. 
Of course, the study also has several limitations that highlight the need for a more cautious interpretation of our findings and offers some guidance for future research. First, in order to ensure an adequate sample size, only one parent (father or mother) of every adolescent participated in the survey. In future studies, researchers could require both parents to participate in the survey. Second, parents' attachment styles were measured using the short version of the Experiences in Close Relationships Scale (ECR), which consists of 12 items (6 items for anxiety and 6 for avoidance; Wei et al., 2007). However, five items had to be deleted because of their low item-total correlations, which may be one of the reasons for the lack of findings related to avoidance. Future studies could use the full version of the ECR, which contains 36 items (Brennan et al., 1998), to assessed parents' attachment style. Additionally, the state adult attachment measure (SAAM) also could be used to measure parents' attachment status in future studies. The Chinese version of SAAM includes 21 items in three subscales: attachment-related security (9 items), avoidance ( 7 items) and anxiety (5 items) (Ma et al., 2012). Finally, a review has shown that parents' attachment style has a strong impact on parenting behaviors (Jones et al., 2015a, b). Therefore, future studies should examine the mediating effect of parenting behaviors on the relation between parents' attachment style and adolescents' RESE.

\section{Implications for Clinical Practice}

The present findings have implications for prevention and intervention efforts targeting early adolescents' parental attachment and RESE. Specifically, fathers' attachment anxiety can influence early adolescents' NEG through adolescents' paternal attachment, and mothers' anxiety can influence adolescents' POS and NEG via adolescents' maternal attachment. These findings suggest that improving adolescents' attachment to anxiously attached parents could alleviate the negative impact of parents' attachment anxiety on adolescents' regulatory emotional self-efficacy. For example, intervention programs targeted anxiously attached parents should be developed to foster intimate parent-adolescent attachment relationships before and during early adolescence. Further, these findings emphasized the importance of developing intervention programs to interrupt the intergenerational transmission of the representation in insecure attached parents via improving their parenting behaviors (van Ijzendoorn et al., 2018; Verhage et al., 2016). Additionally, attachment to parents (i.e., bonding) is positive youth development (PYD) attributes (Qi et al., 2020; Shek et al., 2019a, b), and previous studies have demonstrated that the Project P.A.T.H.S. (Positive Adolescent Training through Holistic Social Programs) developed by Shek is effective in promoting positive development in Chinese secondary school students (Ma et al., 2019; Shek \& Ma, 2012; Shek et al., 2020; Shek et al., 2019a, b; Zhu \& Shek, 2020). Therefore, the Project P.A.T.H.S. could be applied to promote early adolescents' attachment to parents, in turn, improving adolescents' regulatory emotional self-efficacy. 


\section{Conclusion}

Overall, our findings support the notion that parents' attachment anxiety can influence early adolescents' RSES through adolescents' attachment to parents. Nevertheless, given the limited number of studies examining the links between parents' attachment styles, adolescents' parental attachment, and RSES in different cultures, further study is necessary.

Funding This research was supported by the National Social Science Foundation of China [21BSH083].

\section{Declarations}

Conflicts of Interest The authors declare that they have no conflict of interest.

Open Access This article is licensed under a Creative Commons Attribution 4.0 International License http://creativecommons.org/licenses/by/4.0/, which permits use, sharing, adaptation, distribution and reproduction in any medium or format, as long as you give appropriate credit to the original author(s) and the source, provide a link to the Creative Commons licence, and indicate if changes were made. The images or other third party material in this article are included in the article's Creative Commons licence, unless indicated otherwise in a credit line to the material. If material is not included in the article's Creative Commons licence and your intended use is not permitted by statutory regulation or exceeds the permitted use, you will need to obtain permission directly from the copyright holder. To view a copy of this licence, visit http://creativecommons.org/licenses/by/4.0/.

\section{References}

Ainsworth, M. D. S., Blehar, M. C., Waters, E., Wall, S., \& N. . (1978). Patterns of attachment: A psychological study of the strange situation: Hillsdale. Erlbaum.

Armsden, G. C., \& Greenberg, M. T. (1987). The inventory of parent and peer attachment: Individual differences and their relationship to psychological well-being in adolescence. Journal of Youth and Adolescence, 16, 427-454. https://doi.org/10.1007/BF02202939

Bandura, A., Caprara, G. V., Barbaranelli, C., Gerbino, M., \& Pastorelli, C. (2003). Role of affective self-regulatory efficacy in diverse spheres of psychosocial functioning. Child Development, 74, 769-782. https://doi.org/10.1111/1467-8624.00567

Behrens, K. Y., Haltigan, J. D., \& Bahm, N. I. G. (2016). Infant attachment, adult attachment, and maternal sensitivity: Revisiting the intergenerational transmission gap. Attachment \& Human Development, 18, 337-353. https://doi.org/10.1080/14616734.2016.1167095

Bi, S., Haak, E. A., Gilbert, L. R., El-Sheikh, M., \& Keller, P. S. (2018). Father attachment, father emotion expression, and children's attachment to fathers: The role of marital conflict. Journal of Family Psychology, 32, 456-465. https://doi.org/10.1037/fam0000395

Bowlby, J. (1969). Attachment and loss: Vol. 1. Attachment. London: Hogarth Press and the Institute of Psycho-Analysis.

Bowlby, J. (1973). Attachment and loss: Vol. 2. Separation: Anxiety and anger. New York, NY: Basic Books.

Brennan, K. A., Clark, C. L., \& Shaver, P. R. (1998). Self-report measurement of adult attachment: An integrative overview. In J. A. Simpson \& W. S. Rholes (Eds.), Attachment theory and close relationships (pp. 46-76). Guilford Press.

Calkins, S. D., \& Leerkes, E. M. (2011). Early attachment processes and the development of emotional self-regulation. Handbook of self-regulation: Research, Theory, and Applications, 355-373. 
Caprara, G. V., Di Giunta, L., Eisenberg, N., Gerbino, M., Pastorelli, C., \& Tramontano, C. (2008). Assessing regulatory emotional self-efficacy in three countries. Psychological Assessment, 20, 227-237. https://doi.org/10.1037/1040-3590.20.3.227

Caprara, G. V., \& Steca, P. (2005). Affective and social self-regulatory efficacy beliefs as determinants of positive thinking and happiness. European Psychologist, 10, 275-286. https://doi.org/ 10.1027/1016-9040.10.4.275

Cassidy, J. (1994). Emotion regulation: Influences of attachment relationships. Monographs of the Society for Research in Child Development, 59, 228-249. https://doi.org/10.1111/j.1540-5834. 1994.tb01287.x

Coleman, P. K. (2003). Perceptions of parent-child attachment, social self-efficacy, and peer relationships in middle childhood. Infant and Child Development, 12, 351-368. https://doi.org/10.1002/ icd. 316

De Wolff, M., \& van IJzendoorn, M. H. (1997). Sensitivity and attachment: A meta-analysis on parental antecedents of infant attachment. Child Development, 68, 571-591. https://doi.org/10.1111/j. 1467-8624.1997.tb04218.x

Goodman, G. S., Quas, J. A., Batterman-Faunce, J. M., Riddlesberger, M. M., \& Kuhn, J. (1997). Children's reactions to and memory for a stressful event: Influence of age, anatomical dolls, knowledge, and parental attachment. Applied Developmental Science, 1, 54-75. https://doi.org/ 10.1207/s1532480xads0102_1

Grossmann, K., Grossmann, K. E., Fremmer-Bombik, E., Kindler, H., \& Scheuerer-Englisch, H. (2002). The uniqueness of the child-father attachment relationship: Fathers' sensitive and challenging play as a pivotal variable in a 16-year longitudinal study. Social Development, 11, 301337. https://doi.org/10.1111/1467-9507.00202

Hazan, C., \& Shaver, P. R. (1987). Romantic love conceptualized as an attachment process. Journal of Personality and Social Psychology, 52, 511-524. https://doi.org/10.1037//0022-3514.52.3.511

Hu, L. T., \& Bentler, P. M. (1999). Cutoff criteria for fit indexes in covariance structure analysis: Conventional criteria versus new alternatives. Structural Equation Modeling: A Multidisciplinary Journal, 6, 1-55. https://doi.org/10.1080/10705519909540118

Jones, J. D., Cassidy, J., \& Shaver, P. R. (2015). Parents' self-reported attachment styles: A review of links with parenting behaviors, emotions, and cognitions. Personality and Social Psychology Review, 19, 44-76. https://doi.org/10.1177/1088868314541858

Jones, J. D., Ehrlich, K. B., Lejuez, C., \& Cassidy, J. (2015). Parental knowledge of adolescent activities: Links with parental attachment style and adolescent substance use. Journal of Family Psychology, 29, 191-200. https://doi.org/10.1037/fam0000070

Kerns, K. A., Abraham, M. M., Schlegelmilch, A., \& Morgan, T. A. (2007). Mother-child attachment in later middle childhood: Assessment approaches and associations with mood and emotion regulation. Attachment \& Human Development, 9, 33-53. https://doi.org/10.1080/1461673060 1151441

Li, C., Wu, Q., \& Liang, Z. (2019). Effect of Poverty on Mental Health of Children in Rural China: The Mediating Role of Social Capital. Applied Research in Quality of Life, 14, 131-153. https://doi.org/ 10.1007/s11482-017-9584-X

Leung, J. T. Y. \& Fung, A. L. (2021). Editorial: Special issue on quality of life among children and adolescents in Chinese societies. Applied Research in Quality of Life. Advance online publication. https://doi.org/10.1007/s11482-021-09915-9

Lu, Y. Y., Chen, H. T., Wang, H. H., Lawrenz, F., \& Hong, Z. R. (2021). Investigating Grade and Gender Differences in Students' Attitudes toward Life and Well-Being. Applied Research in Quality of Life, 16, 105-127. https://doi.org/10.1007/s11482-019-09746-9

Lu, Y., \& Zhang, Y. (2008). Researches into the relationships among attachment, general self-efficacy and depressive symptoms in junior middle school students. Psychological Development and Education, 24, 55-59. https://doi.org/10.16187/j.cnki.issn1001-4918.2008.01.014(inChinese)

Ma, S., Li, P., Zhang, H., Zhao, M., Li, X., Tian, Z., \& Gillath, Omri. (2012). The Chinese version of State Adult Attachment Measure (SAAM): It's applicability in Chinese college students. Chinese Journal of Clinical Psychology, 20, 5-10. https://doi.org/10.16128/j.cnki.1005-3611.2012.01. 002(inChinese)

Ma, C. M. S., Shek, D. T. L., \& Chen, J. M. T. (2019). Changes in the participants in a communitybased positive youth development program in Hong Kong: Objective outcome evaluation using a one-group pretest-posttest design. Applied Research Quality Life, 14, 961-979. https://doi.org/10. 1007/s11482-018-9632-1 
Madigan, S., Brumariu, L. E., Villani, V., Atkinson, L., \& Lyons-Ruth, K. (2016). Representational and questionnaire measures of attachment: A meta-analysis of relations to child internalizing and externalizing problems. Psychological Bulletin, 142, 367-399. https://doi.org/10.1037/bul0000029

Main, M., Kaplan, N., \& Cassidy, J. (1985). Security in infancy, childhood, and adulthood: A move to the level of representation. In Bretherton \& Waters (Eds.), Growing Points of Attachment Theory and Research. Monographs of the society for research in child development (pp. 66-104). https://doi.org/10. $2307 / 3333827$.

Maxwell, S. E., \& Cole, D. A. (2007). Bias in cross-sectional analyses of longitudinal mediation. Psychological Methods, 12, 23-44. https://doi.org/10.1037/1082-989X.12.1.23

Mikulincer, M., \& Shaver, P. R. (2007). Attachment in adulthood: Structure, dynamics, and change. Guilford Press.

Mikulincer, M., \& Shaver, P. R. (2019). Attachment orientations and emotion regulation. Current Opinion in Psychology, 25, 6-10. https://doi.org/10.1016/j.copsyc.2018.02.006

Mikulincer, M., Shaver, P. R., \& Pereg, D. (2003). Attachment theory and affect regulation: The dynamics, development, and cognitive consequences of attachment-related strategies. Motivation and Emotion, 27, 77-102. https://doi.org/10.1023/A:1024515519160

Muthén, L. K., \& Muthén, B. O. (2012). Mplus User's Guide (7th ed.). Muthén \& Muthén.

Pan, Y., Hu, Y., Zhang, D., Ran, G., Li, B., Liu, C., Liu, G., Luo, S., \& Chen, W. (2017). Parental and peer attachment and adolescents' behaviors: The mediating role of psychological suzhi in a longitudinal study. Children and Youth Services Review, 83, 218-225. https://doi.org/10.1016/j.childyouth.2017.10. 038

Pan, Y., Yang, C., Liu, G., Chan, M., Liu, C., \& Zhang, D. (2020). Peer victimization and problem behaviors: The roles of self-esteem and parental attachment among Chinese adolescents. Child Development, 91, e968-e983. https://doi.org/10.1111/cdev.13319

Pan, Y., Zhang, D., Liu, Y., Ran, G., \& Teng, Z. (2016). Different effects of paternal and maternal attachment on psychological health among Chinese secondary school students. Journal of Child and Family Studies, 25, 2998-3008. https://doi.org/10.1007/s10826-016-0463-0

Pan, Y., Zhang, D., Liu, Y., Ran, G., \& Wang, Z. (2016). Attachment and internalizing symptoms: The mediating role of regulatory emotional self-efficacy among Chinese young adolescents. Personality and Individual Differences, 101, 360-365. https://doi.org/10.1016/j.paid.2016.06.030

Paquette, D., Coyl-Shepherd, D. D., \& Newland, L. A. (2013). Fathers and development: New areas for exploration. Early Child Development and Care, 183, 735-745. https://doi.org/10.1080/03004430. 2012.723438

Preacher, K. J., \& Hayes, A. F. (2008). Asymptotic and resampling strategies for assessing and comparing indirect effects in multiple mediator models. Behavior Research Methods, 40, 879-891. https://doi.org/ 10.3758/BRM.40.3.879

Qi, S., Hua, F., Zhou, Z., Shek, D. T. L. (2020). Trends of positive youth development publications (19952020): A scientometric review. Applied Research in Quality of Life. Advance online publication. https:// doi.org/10.1007/s11482-020-09878-3

Raja, S. N., McGee, R., \& Stanton, W. R. (1992). Perceived attachments to parents and peers and psychological well-being in adolescence. Journal of Youth and Adolescence, 21, 471-485. https://doi.org/10.1007/ BF01537898

Rholes, W. S., Simpson, J. A., \& Blakely, B. S. (1995). Adult attachment styles and mothers' relationships with their young children. Personal Relationships, 2, 35-54. https://doi.org/10.1111/j.1475-6811.1995. tb00076.x

Rholes, W. S., Simpson, J. A., Blakely, B. S., Lanigan, L., \& Allen, E. A. (1997). Adult attachment styles, the desire to have children, and working models of parenthood. Journal of Personality, 65, 357-385. https://doi.org/10.1111/j.1467-6494.1997.tb00958.x

Rice, K. G., Cunningham, T. J., \& Young, M. B. (1997). Attachment to parents, social competence, and emotional well-being: A comparison of Black and White late adolescents. Journal of Counseling Psychology, 44, 89-101. https://doi.org/10.1037/0022-0167.44.1.89

Roelofs, J., Meesters, C., \& Muris, P. (2008). Correlates of self-reported attachment (in) security in children: The role of parental romantic attachment status and rearing behaviors. Journal of Child and Family Studies, 17, 555-566. https://doi.org/10.1007/s10826-007-9174-X

Roisman, G. I., Holland, A., Fortuna, K., Fraley, R., Clausell, E., \& Clarke, A. (2007). The adult attachment interview and self-reports of attachment style: An empirical rapprochement. Journal of Personality and Social Psychology, 92, 678-697. https://doi.org/10.1037/0022-3514.92.4.678 
Selcuk, E., Günaydin, G., Sumer, N., Harma, M., Salman, S., Hazan, C., \& Ozturk, A. (2010). Self-reported romantic attachment style predicts everyday maternal caregiving behavior at home. Journal of Research in Personality, 44, 544-549. https://doi.org/10.1016/j.jrp.2010.05.007

Shaver, P. R., \& Mikulincer, M. (2002). Attachment-related psychodynamics. Attachment \& Human Development, 4, 133-161. https://doi.org/10.1080/14616730210154171

Shek, D. T. L., Dou, D., Zhu, X., \& Chai, W. Y. (2019). Positive youth development: Current perspectives. Adolescent Health, Medicine and Therapeutics, 10, 131-141. https://doi.org/10.2147/AHMT.S179946

Shek, D. T. L., Lin, L., Ma, C. M., Yu, L., Leung, J. T. Y., Wu, F. K. Y., Leung, H., \& Dou, D. (2020). Perceptions of adolescents, teachers and parents of life skills education and life skills in high school students in Hong Kong. Applied Research in Quality of Life. Advance online publication. https://doi. org/10.1007/s11482-020-09848-9

Shek, D., \& Ma, C. (2012). Impact of the Project P.A.T.H.S. in the junior secondary school years: Objective outcome evaluation based on eight waves of longitudinal data. The Scientific World Journal, 2012. Article 170345. https://doi.org/10.1100/2012/170345

Shek, D. T. L., Zhu, X., Leung, J. T. Y., Lee, T. Y., \& Wu, F. K. Y. (2019). Evaluation of the Project P.A.T.H.S. in mainland China: Findings based on student diaries. Research on Social Work Practice, 29, 410-419. https://doi.org/10.1177/1049731517745994

Song, H., Thompson, R. A., \& Ferrer, E. (2009). Attachment and self-evaluation in Chinese adolescents: Age and gender differences. Journal of Adolescence, 32, 1267-1286. https://doi.org/10.1016/j.adolescence. 2009.01.001

Sroufe, L. A. (2005). Attachment and development: A prospective, longitudinal study from birth to adulthood. Attachment \& Human Development, 7, 349-367. https://doi.org/10.1080/14616730500365928

Steinberg, L., \& Silverberg, S. (1986). The vicissitudes of autonomy in early adolescence. Child Development, 57, 841-851. https://doi.org/10.2307/1130361

van Ijzendoorn, M. H. (1995). Adult attachment representations, parental responsiveness, and infant attachment: a meta-analysis on the predictive validity of the adult attachment interview. Psychological Bulletin, 117, 387-403. https://doi.org/10.1037/0033-2909.117.3.387

van Ijzendoorn, M. H., \& Bakermans-Kranenburg, M. J. (2018). Bridges across the intergenerational transmission of attachment gap. Current Opinion in Psychology, 25, 31-36. https://doi.org/10.1016/j.copsyc. 2018.02.014

Verhage, M. L., Schuengel, C., Madigan, S., Fearon, R., Oosterman, M., Cassibba, R., \& van IJzendoorn, M. H. (2016). Narrowing the transmission gap: A synthesis of three decades of research on intergenerational transmission of attachment. Psychological Bulletin, 142, 337-366. https://doi.org/10.1037/bul00 00038

Wei, M., Russell, D. W., Mallinckrodt, B., \& Vogel, D. L. (2007). The Experiences in Close Relationship Scale (ECR)-short form: Reliability, validity, and factor structure. Journal of Personality Assessment, 88, 187-204. https://doi.org/10.1080/00223890701268041

Wilkinson, R. B. (2004). The role of parental and peer attachment in the psychological health and self-esteem of adolescents. Journal of Youth and Adolescence, 33, 479-493. https://doi.org/10.1023/B:JOYO.00000 48063.59425.20

Zhou, Q., Guo, S., \& Lu, H. J. (2020). Well-being and health of children in rural China: The roles of parental absence, economic status, and neighborhood environment. Advance online publication. https://doi.org/ 10.1007/s11482-020-09859-6

Zhou, Z., Shek, D. T. L., \& Zhu, X. (2020). The importance of positive youth development attributes to life satisfaction and hopelessness in mainland Chinese adolescents. Frontiers in Psychology, 11, Article 553313. https://doi.org/10.3389/fpsyg.2020.553313

Zhou, Z., Shek, D.T.L., Zhu, X., \& Dou, D. (2020). Positive youth development and adolescent depression: A longitudinal study based on mainland Chinese high school students. International Journal of Environment Research and Public Health, 17, Article 4457. https://doi.org/10.3390/ijerph17124457

Zhu, X., \& Shek, D. T. L. (2020). Impact of a positive youth development program on junior high school students in mainland China: A pioneer study. Children and Youth Services Review, 114, Article 105022. https://doi.org/10.1016/j.childyouth.2020.105022

Publisher's note Springer Nature remains neutral with regard to jurisdictional claims in published maps and institutional affiliations. 